\title{
ROLE OF PARENTS IN IMPROVING GEOGRAPHY LEARNING MOTIVATION IN IMMANUEL AGUNG SAMOFA HIGH SCHOOL
}

\author{
Oleh \\ Beatus Mendelson Laka'), Jemmi Burdam ${ }^{2)}$ \& Elizabet Kafiar ${ }^{3)}$ \\ 1,2Sekolah Tinggi Keguruan dan Ilmu Pendidikan Biak \\ ${ }^{3}$ Jurusan Pendidikan Guru Sekolah Dasar, Biak Papua \\ Email: ${ }^{1}$ lakamendelson@gmail.com, ${ }^{2}$ jemmiburdam@gmail.com \& \\ 3elizabetkafiar@tyahoo.com
}

\begin{abstract}
Abstrak
Basically the role of parents is more important than the role of a teacher. This is because the first and foremost education is in the family, the child's character's parents. In addition, parents have a lot of time with children from the teacher. Therefore, the role of people is very important for children in providing motivation. Whereas the teacher has very limited time with children because only during school hours. The formulation of the problem in this study is how the role of parents in increasing motivation to learn geography in Immanuel Agung Samofa High School. The purpose of this study was to determine the role of parents in increasing student motivation. This type of research is a type of qualitative research. The method used in this research is interview, questionnaire and documentation. Data analysis techniques in the form of qualitative analysis. The results of this study show that the parents of students at Immanuel Agung Samofa High School have not been maximal in providing motivation for children, this is seen when the teacher checks the learning equipment in the form of stationery, then the presence of students in class during geography learning hours takes place students play, often in and out and often do not take the lesson seriously. as the first teacher for children and parents also who understand more
\end{abstract}

Keywords: Roles, Parents, Learning Motivation \& Geography

\section{PENDAHULUAN}

Masyarakat Indonesia semakin rasional, sehingga lulusan sekolah tidak lagi dipandang dari ijasah saja, melainkan dari konseptual/pemikirannya. Pada perguruan tinggi Gelar kesarjanaan tidak lagi menjadi tujuan utama seseorang dalam mengikuti pendidikan tinggi, melainkan penguasaan ilmu pengetahuan. Akan terjadi seleksi alamiah dimana hanya orang-orang yang benar-benar ingin menguasai bidang ilmu tertentu saja, yang akan melanjutkan ke jenjang pendidikan yang lebih tinggi. Sedangkan orang-orang yang hanya berburu gelar kesarjanaan saja akan menjadi out of date. Pada kondisi itu, maka kinerja perguruan tinggi tidak lagi diukur dalam menghasilkan sebanyak-banyaknya sarjana, melainkan dari kemampuan dalam menghasilkan sebanyak-banyaknya sarjana yang berkualitas, yang diukur dari penguasaan terhadap ilmu pengetahuan.

Rendahnya motivasi belajar siswa sering dianggap sebagai penyebab rendahnya kualitas lulusan sebuah sekolah. Pada kebanyakan sekolah swasta, faktor ini bahkan menimbulkan persoalan dilematis, karena dengan rendahnya motivasi belajar, sebenarnya tidak mungkin siswa dapat menguasai bahan pembelajaran dengan baik, namun harus diluluskan demi kelangsungan sekolah tersebut. Praktik seperti ini menjadi aman dan langgeng, karena secara tidak langsung didukung oleh kebanyakan siswa yang tujuan utamanya hanya sekedar untuk memperoleh ijasah saja, dan bukan untuk menguasai ilmu pengetahuan. Sementara, banyak sekolah yang salah kaprah dalam menerapkan konsep kepuasan pelanggan dalam dunia pendidikan, sehingga memudahkan siswa 
lulus dianggap sebagai memberikan kepuasan terhadap konsumennya.

Dewasa ini, seiring dengan pertumbuhan sekolah yang makin pesat, maka tingkat persaingan di antara sekolah baik itu swasta maupun negeri dalam memperebutkan calon siswa, juga menjadi semakin ketat. Hanya tersedia satu jalan bagi sekolah yang ingin bertahan dalam persaingan tersebut, yaitu melalui kualitas lulusan yang dihasilkannya. Banyak contoh dimana lulusan sekolah tidak diterima di perguruan tinggi bahkan dunia kerja pada suatu perusahaan, karena melalui proses penyeleksian terbukti bahwa ijasah dan gelar kesarjanaan yang dimilikinya tidak sebanding dengan konseptual/pemikirannya. Sekolah dan Perguruan tinggi yang menghasilkan lulusan seperti ini sebenarnya hanya tinggal menunggu waktu saja untuk ditinggalkan calon siswa dan mahasiswanya.

Dapat dikatakan bahwa motivasi belajar siswa merupakan faktor yang paling menentukan dalam menciptakan sarjana yang berkualitas. Sehingga sejalan dengan tekad sekolah SMA IAS untuk menghasilkan para lulusan yang berkualitas, tekad itu kiranya dibarengi dengan upaya untuk meningkatkan motivasi belajar siswanya. Penelitian ini bermaksud untuk mencari tahu, peran orang tua dalam meningkatkan motivasi belajar siswa, sehingga darinya bisa tau bagaimana peran orang tua dalam meningkatkan motivasi siswa agar diperoleh masukan untuk merumuskan kebijakan yang tepat untuk meningkatkannya.

\section{LANDASAN TEORI}

\section{Pengertian Motivasi Belajar}

Motivasi berasal dari kata'motif' yang berarti sebagai daya upaya yang mendorong seseorang untuk melakukan sesuatu. Motif dapat dikatakan sebagai daya penggerak dari dalam dan di dalam subjek untuk melakukan aktivitas-aktivitas tertentu demi mencapai suatu tujuan. Sedangkan motivasi dapat diartikan sebagai daya penggerak yang telah menjadi aktif. Motif menjadi aktif pada saat-saat tertentu, terutama bila kebutuhan untuk mencapai tujuan sangat mendesak/dirasakan. Sardiman, (2016: 73)

Menurut Rianto, (2005 : 53) Motivasi adalah sesuatu yang menggerakkan seseorang atau kelompok orang untuk melakukan atau tidak melakukan sesuatu. Santrock, (2008 : 476) Motivasi dapat berasal dari individu yang bersangkutan maupun dari luar. Motivasi berprestasi dapat dibagi menjadi dua jenis utama. Motivasi berprestasi adalah daya penggerak dalam diri siswa untuk mencapai taraf prestasi setinggi mungkin, sesuai dengan yang ditetapkan oleh siswa yang bersangkutan. Untuk itu siswa dituntut untuk bertanggungjawab mengenai taraf keberhasilan yang akan diperolehnya. Menurut James O. Whittaker, dalam Sadriman, 2016 :73 menyatakan bahwa motivasi adalah kondisi yang mengaktifkan bertingkah laku mencapai tujuan yang ditimbulkan oleh motivasi tersebut, sedangkan belajar sebagai proses di mana tingkah laku diubah melalui latihan atau pengalaman.

Menurut Stagner (dalam Sardiman, 2016

:74) mengatakan bahwa motivasi manusia dibagi menjadi tiga bagian, yaitu:

a. Motivasi biologis, yaitu motivasi dalam bentuk primer atau dasar yang menggerakkan kekuatan seseorang yang timbul sebagai akibat dari kebutuhan organik tertentu seperti lapar, haus, kekuarangan udara, letih dan merasakan rasa sakit. Keperluan-keperluan ini mencerminkan suasana yang mendorong seseorang untuk mengerjakan suatu tingkah laku.

b. Motivasi emosi, seperti rasa takut, marah, gembira, cinta, benci dan sebagainya. Emosi-emosi seperti ini menunjukan adanya keadaan keadaan yang mendorong seseorang untuk bertingkah laku tertentu.

c. Motivasi nilai dan minat. Nilai dan minat seseorang itu bekerja sebagai motivasi yang mendorong seseorang bertingkah laku sesuai dengan nilai dan minat yang dimilikinya. Seseorang yang beragama, tingkah lakunya dipengaruhi oleh nilai 
yang dimilikinya. Nilai dan minat adalah motivasi yang ada hubungannya dengan struktur fisiologi seseorang.

2. Teori Belajar

Belajar adalah sutu aktivitas untuk memperoleh pengetahuan, baik dilakukan secara individual, kelompok, maupun dengan bimbingan guru sehingga perilakunya berubah. Perilaku adalah kebiasaan seseorang, baik yang berupa pengetahuan, sikap, pemahaman, maupun keterampilan. Dan perilaku seseorang dapat berupa behavioral performance (penampakan yang dapat diamati) ataupun behavioral tendency (tidak tampak yang tidak teramati). Kedua perilaku tersebut akan semakin baik jika diperoleh melalui belajar yang benar (Thoifuri, 2013 :99).

Belajar memiliki banyak arti. Belajar adalah suatu proses yang ditandai dengan adanya perubahan pada diri seseorang. Perubahan dalam diri seseorang dapat ditunjukkan dalam berbagai bentuk seperti berubahnya pengetahuannya, pemahamannya, sikap dan tingkah lakunya, keterampilan dan kemampuannya, daya reaksinya, daya penerimaannya dan lain-lain aspek yang ada pada individu (Sudjana, 2002:280). Winkle (dalam Ahmad Susanto, 2016:1), belajar adalah aktivitas mental atau psikis, yang berlangsung dalam interaksi aktif denan lingkungan yang menghasilkan perubahan dalam pengetahuha, pemahaman, keterampilan, nilai, dan sikap. Ngalim Purwanto (dalam Ahmad Susanto, 2016:1) belajar adalah perubahan yang relatif permanen dalam perilaku yang terjadi sebagai hasil dari pelatihan atau pengalaman.

3. Motivasi Belajar

Definisi motivasi belajar banyak diungkapkan oleh para ahli antara lain menurut M. Dalyono memaparkan bahwa motivasi belajar adalah daya penggerak/pendorong untuk melakukan sesuatu pekerjaan, yang bisa berasal dari dalam diri dan juga dari luar (Dalyono, 2005 :55). Dalam kegiatan belajar, motivasi dapat dikatakan sebagai keseluruhan daya penggerak di dalam diri siswa yang menimbulkan, menjamin kelangsungan dan memberikan arah kegiatan belajar, sehingga diharapkan tujuan dapat tercapai (Sardiman, $2011: 102$ )

Menurut Winkel (dalam Aina Mulyana, 2018) mengartikan motivasi belajar adalah segala usaha di dalam diri sendiri yang menimbulkan kegiatan belajr, dan menjamin kelangsungan dari kegiatan belajar serta memberi arah pada kegiatankegiatan belajar sehingga tujuan yang dikehendaki tercapai. Motivasi belajar merupakan faktor psikis yang bersifat non intelektual dan berperan dalam hal menumbuhkan semangat belajar untuk individu.

\section{METODE PENELITIAN}

\section{Research Design}

Penelitian ini menggunakan rancangan penelitian deskriptif kualitatif. Tujuan penelitian deskriptif adalah untuk membuat pencandraan secara sistematis, faktual dan akurat mengenai fakta-fakta, dan sifat populasi dan daerah tertentu. Penelitian ini dilakukan di SMA Immanuel Agung Samofa selama tiga bulan terhitung dari bulan April 2019 sampai dengan bulan Juli 2019. Penelitian ini bermaksud untuk mencari tahu, peran orang tua dalam meningkatkan motivasi belajar siswa, sehingga darinya bisa tau bagaimana peran orang tua dalam meningkatkan motivasi siswa agar diperoleh masukan untuk merumuskan kebijakan yang tepat untuk meningkatkannya. Populasi dari penelitian ini adalah siswa jurusan IPS kelas X, XI, dan XII.

\section{Instruments}

Instrumen dalam penelitian ini berupa, observasi, wawancara, angket/kuisioner dan dokumentasi.

\section{Technique of Data Analysis}

Setelah data dikumpulkan maka, data tersebut dianalisis. Hasil analisis data berupa deskripsi menggunakan tabel frekuensi terhadap data hasil angket dengan menghitung persentase item pernyataan. Selanjutnya data hasil angket dideskripsikan dengan menggunakan rumus yang sudah diadaptasi sebagai berikut: (Arikunto, 2003).

$$
\% \text { Respon }=\frac{\text { jumlah } \text { jawaban }}{\text { jawaban } \text { maksimal }} \times 100 \% .
$$




\section{HASIL DAN PEMBAHASAN}

\section{Findings}

Temuan dalam penelitian ini, berdasarkan hasil observasi peneliti maka terdapat beberapa temuan yang di temukan pada siswa SMA Immanuel Agung Samofa sebagai berikut:

a. Siswa jarang masuk kelas untuk mengikuti pelajaran

b. Orang tua sering abaikan surat panggilan dari sekolah

c. Sering bolos sekolah

d. Motivasi belajar siswa kurang

e. Persiapan siswa dalam hal kelengkapan sekolah berupa buku, cetak, buku tulis, bahkan bolpoint tidak tersedia.

f. Hasil belajar siswa pada semua mata pelajaran kurang

Dari temuan yang peneliti sampaikan diatas maka, peneliti berkesimpulan bahwa peran orang tua masih kurang dalam memberikan motivasi bagi anak di rumah. Sekolah pada intinya sudah menjaankan tugas sebagai guru. Namun semuanya itu menjadi sia-sia tanpa ada topangan dari orang tua siswa tersebut.

\section{Discussion}

Berdasarkan deskripsi sampel diketahui profil responden seperti pada Tabel 1 .

Table 1. Profil Responden berdasarkan kelas

\begin{tabular}{|c|c|c|c|}
\hline No. & $\begin{array}{c}\text { Kelas } \\
\text { IPS }\end{array}$ & Frequency & $\begin{array}{c}\text { Percentage } \\
(\boldsymbol{\%})\end{array}$ \\
\hline 1 & X IPS & 6 & $\mathbf{2 3 , 1}$ \\
\hline 2 & XI IPS & 9 & 34,6 \\
\hline 3 & XII IPS & 11 & 42,3 \\
\hline \multicolumn{2}{|c|}{ Total } & 26 & 100 \\
\hline
\end{tabular}

Penelitian ini menganalisis data dan informasi yang dikumpulkan dari sampel sebanyak 26 siswa, yang terdiri atas 6 siswa kelas X IPS, 9 siswa kelas XI IPS dan 11 siswa kelas XII IPS.
Table 2. Karakter Motivasi Belajar Siswa SMA Immanuel Agung Samofa

\begin{tabular}{|c|c|c|c|c|c|c|c|}
\hline \multirow{3}{*}{ No } & \multirow{3}{*}{ Indikator } & \multicolumn{6}{|c|}{ Mayoritas Siswa } \\
\hline & & X IPS & & XI IPS & & XII IPS & \\
\hline & & $\mathbf{F}$ & $\%$ & $\mathbf{F}$ & $\%$ & $\mathbf{F}$ & $\%$ \\
\hline 1 & $\begin{array}{l}\text { Memiliki } \\
\text { buku cetak }\end{array}$ & Kadang & 60 & Kadang & 70 & Kadang & 45 \\
\hline 2 & Buku tulis & Kadang & 50 & Kadang & 65 & Kadang & 50 \\
\hline 3 & Bolpoint & Sering & 30 & Sering & 30 & Sering & 45 \\
\hline 4 & $\begin{array}{l}\text { Jarang } \\
\text { masuk kelas }\end{array}$ & Selalu & 70 & Selalu & 75 & Selalu & 55 \\
\hline 5 & Sering bolos & Kadang & 50 & Kadang & 60 & Kadang & 45 \\
\hline 6 & $\begin{array}{l}\text { Mengantuk } \\
\text { saat } \\
\text { pelajaran } \\
\text { berlangsung }\end{array}$ & Selalu & 75 & Selalu & 75 & Selalu & 35 \\
\hline 7 & $\begin{array}{l}\text { Bercerita } \\
\text { saat } \\
\text { pelajaran } \\
\text { berlangsung }\end{array}$ & Jarang & 30 & Selalu & 65 & Selalu & 30 \\
\hline 8. & $\begin{array}{l}\text { Menyimak } \\
\text { pelajaran }\end{array}$ & Sering & 45 & Sering & 45 & Selalu & 75 \\
\hline 9 & $\begin{array}{l}\text { Mengerjakan } \\
\text { tugas } \\
\text { mandiri }\end{array}$ & Sering & 50 & Sering & 50 & Sering & 55 \\
\hline
\end{tabular}

Jika motivasi belajar siswa SMA Immanuel Agung Samofa dibandingkan antara kelas X, XI, dan XII IPS, maka dapat dikatakan bahwa motivasi belajar siswa kelas XII IPS relatif lebih baik dibanding motivasi belajar siswa kelas X IPS. Diantaranya, siswa kelas X IPS lebih sering memiliki Bolpoint yang dianjurkan guru dan lebih jarang bercerita saat pelajaran sedang berlangsung. Sementara, meski siswa di kedua kelas X IPS dan kelas XI IPS sama-sama sering menyimak pelajaran dan mengerjakan tugas mandiri serta jarang bolos sekolah, namun proporsi siswa yang melakukannya relatif lebih banyak di kelas X dan kelas XI IPS dibanding kelas XII IPS.

Tabel 3. Faktor yang Mempengaruhi peran orang tua dalam meningkatkan Motivasi Belajar Siswa SMA Immanuel Agung Samofa

\begin{tabular}{|c|l|c|c|c|c|c|c|}
\hline \multirow{2}{*}{ No. } & \multirow{2}{*}{ Indikator } & \multicolumn{6}{|c|}{ Mayoritas Siswa } \\
\cline { 3 - 8 } & & X IPS & & XI IPS & & XII IPS & \\
\cline { 3 - 8 } & Perhatian & Selalu & 60 & Selalu & 70 & Selalu & 80 \\
\hline 2 & $\begin{array}{l}\text { Pemberian } \\
\text { reward/hadiah } \\
\text { dan pujian }\end{array}$ & Kadang & 30 & Kadang & 25 & Sering & 50 \\
\hline 3 & Hukuman & Sering & 30 & Sering & 30 & Sering & 45 \\
\hline 4 & $\begin{array}{l}\text { Menyediakan } \\
\text { kebutuhan } \\
\text { anak }\end{array}$ & Selalu & 70 & Kadang & 75 & Selalu & 55 \\
\hline 5 & $\begin{array}{l}\text { Terlalu } \\
\text { dimanjakan }\end{array}$ & Kadang & 50 & Selalu & 60 & Kadang & 45 \\
\hline
\end{tabular}


Faktor yang mempengaruhi peran orang tua dalam meningkatkan motivasi belajar siswa SMA Immanuel Agung Samofa dibandingkan antara kelas X, XI, dan XII IPS, maka dapat dikatakan bahwa perhatian orang tua terhadap motivasi belajar siswa kelas XII IPS relatif lebih baik dibanding perhatian orang tua terhadap motivasi belajar siswa kelas $\mathrm{X}$ dan kelas XI IPS. Diantaranya, orang tua siswa kelas XII IPS lebih sering memberikan hadiah kepada siswa dibandingkan dengan orang tua kelas X dan kelas XI IPS, pemberian hukuman juga walaupun jawabannya sama dari orang tua kelas X, XI dan kelas XII IPS namun, kelas XII IPS yang lebih baik. Dalam menyediakan kebutuhan anak orang tua kelas X IPS lebih baik dari kelas XI IPS. Sementara, meski siswa di kedua kelas X IPS dan kelas XI IPS samasama sering menyimak pelajaran dan untuk manjakan anak, namun proporsi orang tua yang melakukannya relatif lebih banyak di kelas XI IPS dibanding kelas X dan kelas XII IPS.

\section{PENUTUP}

\section{Kesimpulan}

Peran orang tua dalam meningkatkan motivasi belajar siswa, disini sangat dibutuhkan sebab peran dari orang tua baik orang yang lebih dewasa dari siswa sangat dibutuhkan untuk memberikan perhatian, nasehat dan semangatnya dalam belajar, serta memberikan fasilitas yang dibutuhkan dalam proses belajarnya, sehingga menumbuhkan rasa ingin tahu dan terus belajar dalam menanggapi impian dan cita-citanya. Selain itu peran orang tua peran orang tua sangat dituhukan dalam mengontrol anak terkait dengan kehadiran disekolah, banyak orang tua yang kurang melaksankan perannya ketika anak itu tidak ke sekolah, kemudian jarang mengevaluasi anak di rumah terkait dengan hasil belajar anak tersebut. Hal inilah yang sering dilupakan oleh orang tua tersebut.

Dewasa ini, seiring dengan pertumbuhan sekolah yang makin banyak baik itu sekolah swasta maupun sekolah negeri, maka tingkat persaingan di antara sekolah dalam memperebutkan calon siswa, juga menjadi semakin ketat. Hanya tersedia satu jalan bagi sekolah yang ingin bertahan dalam persaingan tersebut, yaitu melalui kualitas lulusan yang dihasilkannya. Terdapat dua faktor yang membuat seseorang dapat termotivasi untuk belajar, yaitu: (1) motivasi belajar berasal dari faktor internal. Motivasi ini terbentuk karena kesadaran diri atas pemahaman betapa pentingnya belajar untuk mengembangkan dirinya dan bekal untuk menjalani kehidupan; dan (2) motivasi belajar dari faktor eksternal, yaitu dapat berupa rangsangan dari orang lain, atau lingkungan sekitarnya yang dapat memengaruhi psikologis orang yang bersangkutan. Faktor-faktor intrinsik yang mempengaruhi motivasi belajar siswa ialah: (1) minat terhadap bidang ilmu yang dipelajarinya; dan (2) orientasinya dalam mengikuti pendidikan tinggi. Sementara untuk faktorfaktor ekstrinsiknya ialah: (1) kualitas guru dosen yang mengajar; (2) bobot materi kuliah yang diajarkan; (3) metode perkuliahan yang digunakan dosen; (4) kondisi dan suasana ruang kuliah; dan (5) fasilitas perpustakaan yang dapat dimanfaatkan oleh siswa.

\section{DAFTAR PUSTAKA}

[1] Anton Rianto, 2005. Born to Win: Kunci Sukses yang Tak Pernah Gagal. Jakarta: Gramedia Pustaka Utama

[2] Arikunto, Suharsimi. 2013. Prosedur Penelitian Suatu Pendekatan Praktik. Jakarta: Rineka Cipta.

[3] Jhon W. Santrock, 2008. Adolescence. Jakarta: Erlangga

[4] Nana Sudjana. 2002. Penilaian Hasil Proses Belajar Mengajar. Bandung: Remaja Rosdakarya

[5] Sardiman AM. 2016. Interaksi dan Motivasi Belajar Mengajar, Jakarta: Rajawali Press

[6] Susanto Ahmad. 2016. Teori Belajar dan Pembelajaran di SD. Jakarta. Kencana

[7] Thoifuri. 2013. Menjadi Guru Inisiator. Semarang. Media Campus Publishing

[8] https://ainamulyana.blogspot.com. Diakses pada tanggal 28 April 2018 
HALAMAN INI SENGAJA DIKOSONGKAN 